\title{
Autism Tsunami: the Impact of Rising Prevalence on the Societal Cost of Autism in the United States
}

\author{
Mark Blaxill $^{1}$ (D) Toby Rogers $^{2}$ [D $\cdot$ Cynthia Nevison $^{3}$
}

Accepted: 29 May 2021 / Published online: 18 July 2021

(c) The Author(s) 2021

\begin{abstract}
The cost of ASD in the U.S. is estimated using a forecast model that for the first time accounts for the true historical increase in ASD. Model inputs include ASD prevalence, census population projections, six cost categories, ten age brackets, inflation projections, and three future prevalence scenarios. Future ASD costs increase dramatically: total base-case costs of $\$ 223$ (175-271) billion/year are estimated in 2020; \$589 billion/year in 2030, \$1.36 trillion/year in 2040, and \$5.54 (4.29-6.78) trillion/year by 2060, with substantial potential savings through ASD prevention. Rising prevalence, the shift from child to adult-dominated costs, the transfer of costs from parents onto government, and the soaring total costs raise pressing policy questions and demand an urgent focus on prevention strategies.
\end{abstract}

Keywords Autism spectrum disorder $\cdot$ Cost $\cdot$ Future cost projections $\cdot$ ASD prevalence $\cdot$ Time trends

\section{Introduction}

As reported prevalence rates of autism spectrum disorders (ASD) have risen during the last three decades, both in the United States (CDC, 2000, 2014/ADDM; Nevison et al., 2018) and around the world (Blaxill, 2004; McDonald \& Paul, 2010), increasing attention has been focused on assessing the future cost of autism on society. An emerging body of analysis has addressed the cost of autism with increasing specificity, especially in the United States and the United Kingdom. These analyses have followed a deliberate progression from small pilot surveys of families to collect data on out-of-pocket expenses, service utilization, and lost parental income (Jarbrink et al., 2003) to larger, more detailed family surveys (Jarbrink, 2007). More recently the analyses have extended to full-country cost estimates based on population prevalence and with detailed cost models per individual, calculated variably based on age and severity (Knapp et al., 2009) and to cross-country cost estimates

Mark Blaxill

mblaxill@hollandcenter.com

Holland Center, Minnetonka, MN, USA

2 Pasadena, CA, USA

3 Institute for Alpine and Arctic Research, University of Colorado, Boulder, CO, USA based on expanded model inputs with cost segmentation by age, severity and cost category (Beuscher et al., 2014). Finally, they have progressed to forecasts of full-country costs (including in-depth inflation forecasts) using a base case and multiple scenarios that vary with respect to prevalence, intellectual disability ratio, prevalence trends and intervention success (Leigh \& Du, 2015) and to state level projections and scenarios of the lifetime cost of autism (Cakir et al., 2020).

With one exception (Cakir et al., 2020), the full-country analyses have primarily assumed constant autism prevalence over time across the entire population for their cost estimates. In one of the publications that assumed constant prevalence, one of the six scenarios forecasting future costs incorporated a population estimate with a real increase in prevalence, but without a birth-cohort specific population model (Leigh \& Du, 2015). In this one scenario, ASD population prevalence for the entire U.S. was increased in a stepwise fashion, using ADDM rates for 8-year-olds born in 1992 and 2002-2004 of $0.67 \%$ ( 1 in 149, ADDM 2000) and $1.47 \%$ (1 in 68, ADDM 2010-2012), respectively, and applying those rates to the entire population. Although the most recent prevalence estimates substantially exceed the values used in that scenario, the future U.S. autism cost, after including inflation, still rose to a sobering $\$ 1.01$ trillion per year in 2025 , or $3.6 \%$ of GDP. In the single study that relied on rising prevalence numbers, rate increases were 
incorporated in a model that calculated the "lifetime social cost" (not an annual cost) of ASDs (Cakir et al., 2020). In that analysis, for the modeled population of two million U.S. autism cases born from 1990 to 2019, total lifetime costs came to seven trillion 2019 dollars. The model was then projected forward through 2029 under two prevalence assumptions: a prevalence rate for the birth years 2020-2029 that would not change from its recent high level of $2.47 \%$ (Zablotsky et al., 2017) and a trend-line increase in the decadal average prevalence for children born from 2020 to 2029 to $4.46 \%$. In the first scenario, the lifetime social cost of autism for individuals born from 1990 to 2029 reached $\$ 11.5$ trillion. In the second, the lifetime social cost with continuing increases approached $\$ 15$ trillion (Cakir et al., 2020).

In support of the Cakir et al., 2020 approach, the increasingly regular surveys of ASD prevalence, especially within the U.S., suggest a clear increase in prevalence over time. The earliest surveys of autism rates focused on the state level (Treffert, 1970/WI, Burd, 1987/ND, Ritvo et al., 1989/UT) and reported low rates. Starting in the late 1990s, researchers utilized administrative databases in California and the U.S. Department of Education to provide information on autism times trends (Byrd et al., 2002; California DDS, 1999, 2003; Newschaffer et al., 2005) and reported increasing prevalence rates. In parallel, the CDC published prevalence studies that focused on the full range of ASDs, generally affirming higher rates (CDC, 1998/Brick, Bertrand et al., 2001/Brick NJ, Yeargin-Allsopp, 2003/MAADSP) but reaching no conclusions on time trends.

Following these surveys, the CDC established the Autism and Developmental Disabilities Monitoring (ADDM) Network, which began publishing bi-annual reports on autism prevalence (CDC/ADDM, 2007-2020). The ADDM Network measures a single birth-year cohort at a time with a focus on prevalence in 8-year-olds. These "constant-age tracking" surveys have had the advantage of reducing ascertainment bias in time trend assessment and the disadvantage of possible under-ascertainment of Asperger's syndrome, which has a later average age of diagnosis, in the range of 6.2 to 8.1 years old (Lingam et al., 2003; Mitroulaki et al., 2020). The ADDM surveys have reported an Asperger's proportion of $9-11 \%$ of surveyed populations (ADDM 2008, 2010 and 2012 reports) while also reporting ASD rate increases from 1 in 149 (ADDM 2000 report) to 1 in 54 (ADDM 2018 report), with rates as high as 1 in 14 in certain school districts (Shenouda \& Zahorodny, 2021). Most recently, the National Center on Health Statistics (NCHS) and the Census Bureau have published a series of household surveys of the US population asking a version of the question, "Has a doctor or health professional ever told you that [sample child] had Autism, Asperger's disorder, pervasive developmental disorder, or autism spectrum disorder?" These surveys (Blumberg et al., 2013; Kogan et al., 2009,
2018; Zablotsky et al., 2017) collect more modest detail on ASD diagnoses in children aged 3-17 years old, but the inclusion of older age cohorts allows for fuller ascertainment of Asperger's cases. Both the Census Bureau and the NCHS surveys report higher prevalence rates than the ADDM Network and have ranged from 1 in 36 to 1 in 40 in the most recent reports (Kogan et al., 2018; Zablotsky et al., 2017).

Despite this growing body of literature on autism prevalence, there is still no single authoritative source of population trends in the U.S. ASD rates over time and by severity. The early surveys focused primarily on the narrower and more severe definition of autism-infantile autism-as described in the DSM III, with some attention to the broader concept of the Pervasive Developmental Disorders (PDDs), but offered limited insight on time trends. Administrative databases provided more precise birth year reporting (CA DDS and IDEA), which enabled better time trend assessment but also allowed for potential inconsistency in ASD coverage (Byrd et al., 2002; MacFarlane \& Kanaya 2009; Nevison et al., 2018). The ADDM Network reports have attempted to improve on the methods of these prior surveys: each ADDM report estimates prevalence on a specific birth cohort, while the 2008, 2010 and 2012 reports detailed the respective proportions of $\mathrm{PDD} /$ autistic disorder (AD), $\mathrm{PDD} /$ not otherwise specified (PDD-NOS) and PDD/Asperger's Syndrome (AS). By contrast, the household surveys cover a wide range of birth years in each snapshot with some, but variable detail on prevalence by age cohort; these surveys report substantially higher prevalence rates than other sources, although the time trends appear to run parallel to ADDM estimates. The DSM-5 criteria, adopted in 2013, replaced the nomenclature of "pervasive developmental disorders" (PDDs) that had been utilized from 1980 to 2013 in DSM-III, III-R and DSM-IV with "autistic spectrum disorders" (ASDs) and eliminated altogether the three primary subcategories of the PDDs-AD, PDD-NOS and AS (DSM-IV only) (APA, 2013). For this reason, the ability to compare past surveys based on previous nomenclature and subcategories with more recent assessments based on the DSM- 5 criteria has been impacted.

Meanwhile, most analyses to date of the societal costs of autism have substantial limitations. Many have focused on individual family burdens rather than populations as a whole. When they report on populations, they often ignore time trends and the concomitant possibility of rising costs. When they report on prevalence over time, they typically do not consider or address the abundant evidence described above of increasing rates. These limitations have important consequences for calculations of ASD costs. To the extent their prevalence estimates lag behind the latest evidence, they tend to underestimate the costs of current childhood populations. To the extent their past and projected ASD rates assume unchanging prevalence, they 
likely overestimate the cost of current adult populations and underestimate the increased cost of future adult populations. To the extent they lack a detailed assessment of ASD time trends, they likely mischaracterize the changing shape of the future ASD costs. Finally, to the extent that they neglect important shifts in the mix of future autism costs-e.g. with educational costs stabilizing while residential and medical costs surge-they risk leaving important dynamics for the well-being of individuals with ASD unaddressed.

In this study, we attempt to remedy these limitations by developing a more comprehensive and accurate U.S. cost model. We begin with the best available long-term ASD prevalence rates using a snapshot that encompasses birth cohorts from 1931 to 2016. To convert that snapshot to a current cost for the full U.S. population, we apply (with substantial amendments and updates) the most thorough recent estimates of costs per ASD individual. These cost estimates have been refined over the years in the cost burden literature and are partitioned into six different categories (e.g., education, individual productivity loss, etc.) (Beuscher et al., 2014; Cakir et al., 2020). We develop models that forecast ASD prevalence through 2060, using multiple future scenarios to incorporate the potential impact of rising prevalence on the future cost burden of ASDs. These forecast models are inspired by previous work (Cakir et al., 2020; Leigh \& $\mathrm{Du}, 2015)$ but adopt a different set of prevalence scenarios that extend further into the future and consider the possibility of prevention. We develop annual cost estimates using both constant 2018 dollars as well as current dollars, using three indices to project the effects of inflation (Leigh $\& \mathrm{Du}, 2015)$. Finally, we apply the cost category analysis to historic and projected models of the U.S. ASD population to provide better and more finely resolved estimates of how the annual ASD cost burden in the U.S. will shift over time.

Accurate economic estimates of the societal cost of disease are essential for sound law and policymaking. Autism cost assessments are especially important because the costs of autism are larger than for other disorders (e.g., cancer, stroke, and heart disease) and because autism strikes in childhood and affects the entire lifespan (Beuscher et al., 2014; BJFM, 2014). As we show in this paper, the cost patterns with autism are also unique in that sharply rising prevalence has created a massive wave of costs that will continue for decades if policymakers and the public fail to grasp the possibility and importance of prevention. Paradoxically, the future costs of autism loom so large that, rather than responding with a sense of urgency as one might expect, policymakers thus far have generally failed to engage with the policy implications at all (Rogers, 2019). We hope this paper will serve as a wakeup call for the public health emergency that the societal cost of autism represents to the economic future of the U.S.

\section{Methods}

We developed annual cost of disease projections for ASD through 2060 based on a model with four elements:

1. Historical autism prevalence estimates with time trend data for both severe and full spectrum autism rates. We used California time trend data (updated from Nevison et al., 2018) for the severe autism time series and a broader assessment of the ASD prevalence literature to estimate a full ASD prevalence including milder cases.

2. A matrix of costs per individual for multiple categories applied to multiple age cohorts. We followed the method of Beuscher et al. (2014) with an expanded approach using more refined age cohort and an updated literature review of individual cost elements all expressed in 2018 dollars (Cakir et al., 2020; Rogge \& Jansen, 2019)

3. Projections of the future size of the ASD population based on three scenarios for future ASD prevalence. We projected the U.S. population for the years 2020-2060 using Census Bureau forecasts by age cohort and applied future prevalence rates to that population using three scenarios-Base Case, Low, and Prevention—for both severe and broad spectrum ASD rates.

4. Inflation projections by cost component. Following Leigh and Du (2015) we applied three different inflation indexes to our projections of each future cost per individual component.

Combining those elements allowed us to estimate a total ASD cost by year for the United States, both in total and by cost component.

\section{General Approach}

Our approach is based on observed autism prevalence in the California Department of Developmental Services (DDS) caseload, for which data are available from birth years 1931-2016. Prevalence is then projected forward from birth year 2014-2060 using three different scenarios. Since, as described below, severe autism accounts for only about one half to one third of all ASD, we estimate the total prevalence of ASD by multiplying severe prevalence from CDDS by a range of empirical scalars (2.1-3.5). Population projections through 2060 from the U.S. Census Bureau are used to translate prevalence into absolute counts of severe and milder ASD, each resolved annually by age. The counts are multiplied by six different cost categories, with costs partitioned by age group and distinguished between severe and milder ASD. Finally, an inflation index relative to base year 2018 is applied and 
compounded to each of the projection years from 2020 to 2060. Overall costs are calculated as a function of birth year, census projection year, future prevalence scenario, and cost category indices. Our calculations permit the isolation of any individual index or set of combined indices by integrating over the remaining indices. Appendix provides more details about the equations used. The components of the cost calculation are described in more detail below.

\section{Historical Prevalence of ASD}

\section{Severe ASD from California DDS}

Statewide autism counts from the California Department of Developmental Services (CDDS) were used as the basis for the estimation of severe autism prevalence. The primary datasets were an age-resolved CDDS snapshot for 2020 tabulating the number of individuals receiving services for autism, resolved by individual birth year from 1953 to 2016 (updated by 3 years from the 2017 snapshot presented in Nevison et al., 2018). The 2020 data were supplemented with birth year 1931-1952 autism counts from the 2017 CDDS snapshot to extend the curve back to birth year 1931. The 2020 snapshot was used as the basis for the Base Case and Prevention scenarios discussed below. An additional age-resolved CDDS snapshot for 2014, resolved by individual birth year from 1931 to 2010, was used in the estimation of the Low future scenario discussed below. The CDDS autism counts were converted to prevalence in $\%$ using California live birth data as denominators, as per Nevison et al. (2018).

The 2020 snapshot used the DSM-5 category of autism spectrum disorder (ASD) (APA, 2013), while the 2014 snapshot was the most recently available CDDS dataset that was still using the DSM-IV definitions, in which Autistic Disorder (AD) diagnoses were distinguished from milder ASDs (APA, 1994). Historically, CDDS has focused on "full syndrome" cases, which were generally diagnosed with AD (CDDS, 1999, 2003), the most severe expression of autism. Furthermore, to qualify for CDDS services, individuals must have a level of impairment that rises to the level of a "developmental disability," where the latter is defined as a non-physical, substantial disability that is expected to continue indefinitely. In addition to an autism diagnosis, CDDS requires that individuals demonstrate significant functional disability in three out of seven life challenges, which include self-care, language, learning, mobility, self-direction, capacity for independent living and economic self-sufficiency in order to qualify for services (Autism Society 2015).

\section{Milder Autism Prevalence}

To estimate the complete prevalence of ASD, we reviewed the ratio of ASD/AD reported in the literature (where ASD encompasses and thus includes AD), including early snapshot surveys (Bertrand et al., 2001; Burd, 1987; Treffert, 1970) 8 year-old constant age tracking data (CDC, 2007, 2009, 2012, 2014, 2016, 2018, Gurney et al., 2003;); and National Health Interview Surveys of 3-17 year-olds (Blumberg, 2013; Kogan et al, 2009; Zablotsky et al., 2017). The literature review yielded $\mathrm{ASD} / \mathrm{AD}$ ratios ranging from about 2.1-3.5. We therefore scaled the CDDS prevalence data (which as described above were assumed to reflect $A D$ cases) by multipliers ranging from 1.1-2.5 to estimate the additional prevalence of individuals with milder ASDs. The $1.1-2.5$ range in scalars is propagated through the cost calculations and is represented in the figures as a window of uncertainty surrounding the mean value (1.8) of the range.

\section{Cost Categories}

We applied to our population estimate a cost per individual per year guided by the approach of Buescher et al., 2014, but with substantial revisions and updates. Buescher et al., defined per person costs for a number of cost categories for ASD cases with intellectual disability (ID) and then generally cut those in half for ASD cases without ID. In our calculations, we make a conceptually similar distinction between severe (i.e., CDDS) and milder ASD, but this is not directly analogous to Buescher et al.'s with and without ID distinction, since not all CDDS cases are identified as having ID.

\section{Non-medical Services}

We defined a "Non-medical Services" category, based on recent data compiled for 2017-2018 (CDDS, 2019), which encompasses three of Buescher et al.'s categories: Accommodation, Employment Support, and Non-Medical Services. The Non-medical Services category also includes community care, respite care and day care programs (Leigh et al., $2015)$. While Buescher et al. defined only three age groups $(0-5,6-17,18-64$ years), we expanded these into 10 age groups 0-2, 3-6, 7-11, 12-21, 22-31, 32-41, 42-51, 52-61, $62-71,72-100)$ both for closer matching of needs to age and for compatibility with the age groups defined by CDDS (2019). We interpolated these 10 age groups to define as continuous annual functions of age, which were related to birth year via Equation 5 in the Appendix. We assumed that the same miscellaneous non-medical costs applied to those severely and more mildly affected, due to a lack of appropriate data to distinguish the two. 


\section{Individual Productivity Loss}

We used per person annual production values for 2018 in the United States from Davenport et al., 2019 (their Figure A25). These were broken down by gender, with substantially higher values for males than females, and divided into 5-year age intervals beginning at age 15 and extending through age $80+$. Since these intervals did not directly coincide with our Miscellaneous Services cost category age intervals, we took the appropriate weighted average of the Davenport et al. data (e.g., for adults $22-31$, we added the production values for age $20-24$, $25-29$ and $30-34$, weighted by $0.3,0.5$ and 0.2 , respectively). We further weighted the production values by the 80:20 male:female ratio of ASD observed in the U.S. (CDC, 2018). We surveyed the literature on employment patterns in adults with autism in order to estimate competitive (currently working, full-time, paid) employment rates rather than mere participation in work. Much of this literature focuses on small samples composed largely of High Functioning Autism (HFA)/Asperger's workers (Eaves \& Ho, 2008; Jarbrink et al., 2007; Jennes-Cousennes et al., 2006; Larsen \& Mauridsen, 1997; Mawhood \& Howlin, 1999; Rumsey et al., 1985; Szatmari et al., 1989; Venter et al., 1992) and report rates ranging from 7 to $44 \%$. A few more recent surveys (Farley et al., 2018; Ohl et al., 2017; Roux et al., 2013; Shattuck et al., 2012) that have larger and more diverse samples, report competitive employment rates in a similar range of $7-34 \%$. For our model, we assumed a $100 \%$ loss of productivity for severe ASD cases and a 70\% loss of productivity for milder ASD cases.

\section{Parent Productivity Loss}

We assumed $75 \%$ loss of maternal productivity for children with severe ASD and 25\% loss of maternal productivity for children with milder ASD.

For all ages we assumed zero loss of paternal productivity. These assumptions are based on Cidav et al., (2012), who found that on average mothers of children with ASD had a 56\% loss of productivity compared to mothers of neurotypical children while fathers showed no statistical difference in productivity. We estimated the mother's age range for each of the ASD age groups in Table 1 by adding 28 (our assumed average maternal age at birth Martin et al., 2021]) to the children's age. We then matched the maternal age to the per person annual production values for the United States (Davenport et al., 2019) and scaled by 0.75 (severe) and 0.25 (mild). We assumed 0 parental productivity loss for individuals with ASD age 52 or older.

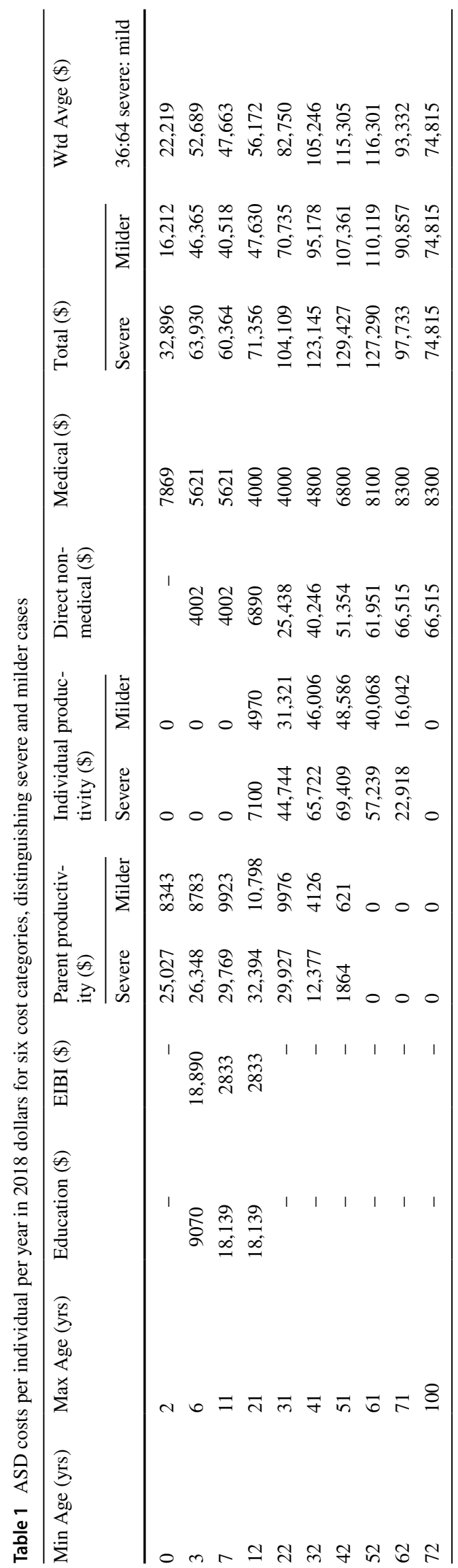




\section{Education}

A comprehensive national survey of special education costs reported the cost of educating a large sample of children with disabilities, including autism, to the cost of regular education (Chambers et al., 2002, 2003). They found an incremental cost per student with autism of $\$ 12,243$ (\$18,139 in 2018 dollars). Notably autism was the highest cost disability and this analysis excluded early intensive behavioral intervention. We applied this estimate for school-aged children to our model for children ages 5-21. A more recent legislative analyst's report in California found that incremental cost for children with disabilities in general was $\$ 17,000$ in the 2017-2018 fiscal year, which suggests that autism costs were likely even higher in California during the report period (Petek, 2019).

\section{Early Intervention/Behavioral Intervention (EIBI)}

Many children with autism receive EIBI services, usually for Applied Behavioral Analysis. Some studies (e.g., Ganz, 2007) have included EIBI in their cost per individual analyses, some (Buescher et al., 2014) are unclear how they approach EIBI and others (Cakir et al., 2020) exclude EIBI costs. We estimated the average individual EIBI cost using an average full time $(40 \mathrm{~h})$ EIBI program cost of $\$ 63,500$ (Amendah et al., 2011; Butter et al., 2003; Chasson et al., 2007; Cidav et al., 2017; Jacobsen et al., 1998; Sallows \& Graupner, 2005), with an average EIBI utilization rate of twelve hours per week (Yingling \& Bell, 2019), with a drop off rate of 86\% after early childhood (Ganz, 2007 adjusted for discounting). We made no assumption about differential EIBI usage in severe and mild cases.

\section{Medical Costs}

We adopted the analysis of Zuvekas et al. (2020) for incremental direct medical costs in ASD children of \$5621. For infants with ASD we multiplied childhood costs by a factor of 1.4 to reflect higher medical costs in infancy (Shimabukuro et al., 2008). For adults, we assumed a range of incremental costs starting at $\$ 4000$ in young adults (Ganz, 2007, adjusted for discounting) and rising with age to $\$ 8300$ in the elderly (Ganz, 2007; Vohra et al., 2017; Zerbo et al., 2019. We made no assumption about differences in medical costs across severe and mild cases.

\section{Scenarios of the Future ASD population size}

\section{Census Data and Future U.S. Population Projections}

We used United States Census Bureau population projection tables, which were based on the 2016 base total U.S. population and provided future projections every 5 years from 2020 to 2060 (US Census Bureau, 2018). The populations were resolved by 8 age groups $(0-4,5-13,14-17$, $18-24,25-44,45-64,65-84,>85$ (we treated this last group as $85-100$ ). These age groups were interpolated to individual yearly ages, assuming an even distribution among the annual birth cohorts within each group. While this assumption is probably not true, particularly for the $85-100$ group, this latter group had a relatively small effect on our calculations. Similarly, we did not consider uncertainty in future total population estimates, since these were likely to be overshadowed by the larger uncertainty in the future ASD prevalence.

\section{Future Scenarios of Rasd}

Future scenarios, resolved annually as a function of birth year (ibyr), were constructed for ASD prevalence, representing Low and Base Case extensions of the CDDS ageresolved snapshot data through 2060. These were modeled as an increasing logistic function using Eq. 1

$\mathrm{R}_{\text {scenario }}(\mathrm{ibyr})=\frac{\operatorname{Rinf}}{1+\left(\exp ^{-a\left(i b y r-t_{\text {half }}\right)}\right)}$

where $R$ represented future severe ASD prevalence and the parameters $R_{\text {inf }}, \alpha$ and $t_{\text {half }}$ were derived from a logistic fit to CDDS snapshot data using the matlab routine fit_logistic.m (https://www.mathworks.com/matlabcentral/fileexchange/ 41781-fit_logistic-t-q). Here, $R_{\text {inf }}$ is the final or asymptotic ASD prevalence at time infinity, and $\alpha t_{\text {half }}$ are parameters

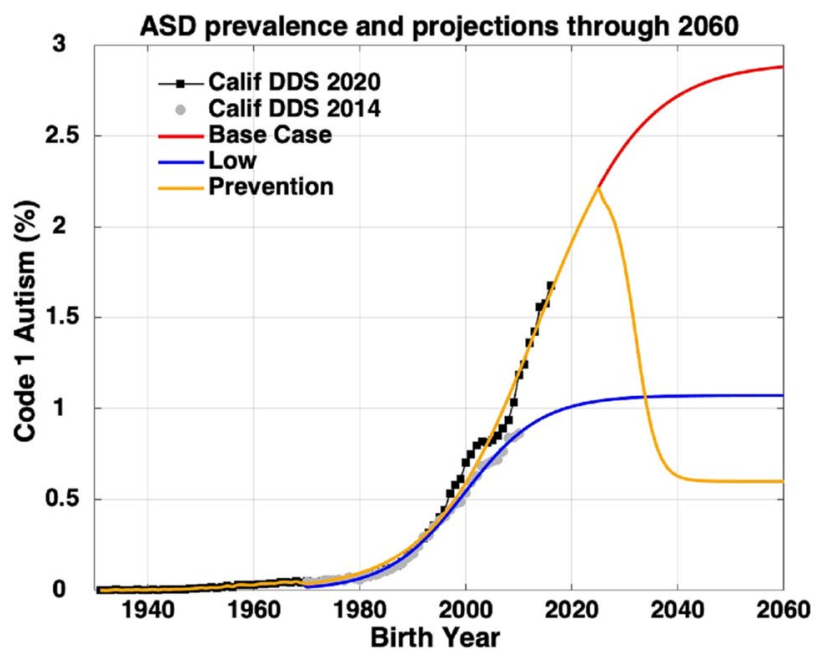

Fig. 1 Three scenarios for future growth in US severe autism prevalence, which are assumed to follow a logistic growth equation. Black squares show the California DDS 2020 ASD prevalence snapshot, which is used as the basis for the Base Case and Prevention scenarios. Gray circles show the California DDS 2014 snapshot, which is used as the basis for the Low scenario 
describing the rate of growth. We used two different sets of snapshot data to provide a range of uncertainty in the future evolution of ASD (Fig. 1).

Base Case Scenario We used parameters derived from a logistic fit to the 2020 California DDS snapshot of ASD prevalence (the most recently available) extending from birth year $1970-2016$. $\mathrm{R}_{\text {inf }}$ from the fit is $2.9 \%$ (Fig. 1).

Low scenario We used parameters derived from a logistic fit to the 2014 CDDS snapshot of ASD prevalence extending from birth year 1970-2010. The Low scenario already underestimates prevalence reported by CDDS in the 2020 snapshot in the most recent years (Fig. 1), but this scenario was included because the 2014 data are the most recently available snapshot that still use DSM-IV criteria. The $\mathrm{R}_{\text {inf }}$ value from the 2014 snapshot logistic fit is $1.07 \%$.

Prevention Scenario We created a prevention scenario based on a variation of the negative logistic curve (Eq. 2).

$$
R_{\text {prevention }}(\text { ibyr })=\frac{R_{\max }-R_{\min }}{1+\left(\exp ^{a x\left(i b y r-t_{\text {halfdec }}\right)}\right)}+R_{\min }
$$

The Prevention scenario is included as an illustrative example of what might be possible if strategies for reducing ASD risk are identified and addressed in the near future. While many of the parameter choices are open for debate, we used the following assumptions and values: $R_{\text {prevention }}$ was assumed to follow the Base Case prevalence scenario until 2025 , the assumed birth year of prevalence decline. $R_{\max }$ was set equal to $R_{\text {basecase }}(2021)$. Thereafter, $R_{\text {prevention }}$ was assumed to decrease quickly at an accelerated (relative to the increase over the last 40 years) rate $\alpha \mathrm{x}$, where $\mathrm{x}$ was set at 5 and $t_{\text {halfdec }}$ was set at birth year 2032. In the prevention scenario, autism prevalence asymptotes to a target prevalence $\mathrm{R}_{\min }$, which was set to the CDDS autism prevalence in birth year 2013 of $0.6 \%$ observed among white children in wealthy counties in California (Nevison \& Parker, 2020).

All three scenarios are assumed to reflect the most severe autism cases, and the total ASD prevalence is calculated by adding in the milder ASD cases, estimated using the scaling approach and scaling factors described above.

\section{Inflation Projections}

Our per person cost category estimates are based on 2018 dollar values. To account for inflation in projection years 2020-2060, we followed the approach of Leigh and Du (2015), who distinguished between projections for medical, non-medical and productivity-related inflation and applied different projection methods to each of these three cost categories. We applied the non-medical adjustment factor to education, EIBI, and Direct Non-Medical services the productivity adjustment factor to Parent and Individual Productivity Loss, and the medical adjustment factor to Direct
Table 2 Inflation adjustment factors compounded annually for three price indices at 5-year projection intervals, using from a base year of 2018

\begin{tabular}{llll}
\hline Year & Medical & Non-medical & Productivity \\
\hline 2016 & 0.9282 & 0.9185 & 0.9537 \\
2018 & 1.000 & 1.000 & 1.000 \\
2020 & 1.087 & 1.065 & 1.065 \\
2025 & 1.370 & 1.259 & 1.260 \\
2030 & 1.737 & 1.477 & 1.468 \\
2035 & 2.196 & 1.729 & 1.710 \\
2040 & 2.776 & 2.024 & 1.992 \\
2045 & 3.509 & 2.369 & 2.320 \\
2050 & 4.436 & 2.773 & 2.703 \\
2055 & 5.608 & 3.246 & 3.149 \\
2060 & 7.090 & 3.799 & 3.668 \\
\hline
\end{tabular}

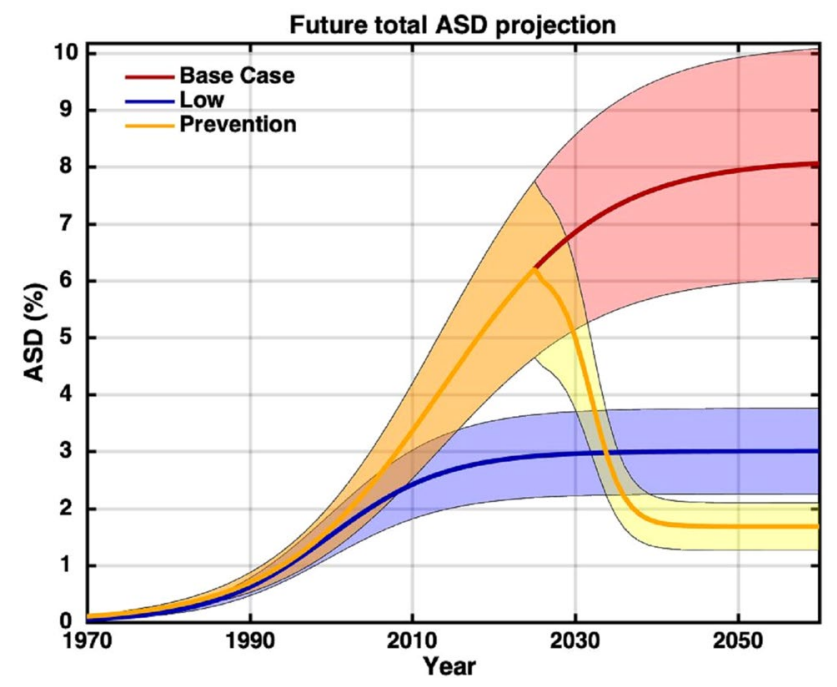

Fig. 2 Three scenarios for future growth in US total ASD prevalence, using a 2.1-3.5 range of multipliers applied to the severe prevalence curves in Fig. 1. The shaded areas reflect the uncertainty in this scalar approach of converting prevalence of severe autism from California DDS into total ASD, with the mean value shown as a solid line

Medical Costs. Table 2 shows these adjustment factors compounded annually for 2020-2060 (at 5 year intervals).

\section{Results}

Severe ASD prevalence in the 2020 California DDS snapshot shows an ongoing upward trajectory, particularly among Black and Hispanic children, reaching 1.7\% overall among 4 year-olds born in 2016 (Fig. 1; Supplementary Fig. 1). Extrapolating the 2020 data forward with Eq. 1 leads to a severe ASD prevalence of 2.9\% in 2060 in the Base Case scenario, while extrapolation of the 2014 California DDS 
snapshot leads to a severe ASD prevalence of $1.07 \%$ in the Low scenario (Fig. 1). This spread (1.07-2.9\%) in severe prevalence corresponds to a total ASD prevalence range of $2.2-10 \%$ by 2060 , using the $2.1-3.5$ multipliers (Fig. 2). The Prevention scenario initially follows the steeper trajectory of the Base Case scenario but declines beneath the Low scenario by 2028 , plateauing at $0.6 \%$ severe and $1.3-2.1 \%$ total ASD after about 2040 (Figs. 1 and 2).

The total cost of ASD in 2020, according to the Base Case (best guess) scenario, is estimated at $\$ 223 \pm 48$ billion (Fig. 3; Table 3). These costs increase to $\$ 5.5 \pm 1.2$ trillion by 2060 , accounting for inflation. The Prevention scenario leads to a substantial reduction in the economic burden (\$3.7 \pm 0.8 trillion by 2060), while the total price tag for the Low scenario is $\$ 170 \pm 37$ billion in 2020 and $\$ 2.8 \pm 0.6$ trillion, respectively, by 2060, accounting for inflation. If inflation is not taken into account, the total cost of ASD in 2018 dollars under the Base Case scenario is estimated at $\$ 1393 \pm 310$ billion in 2060 (Table 3).

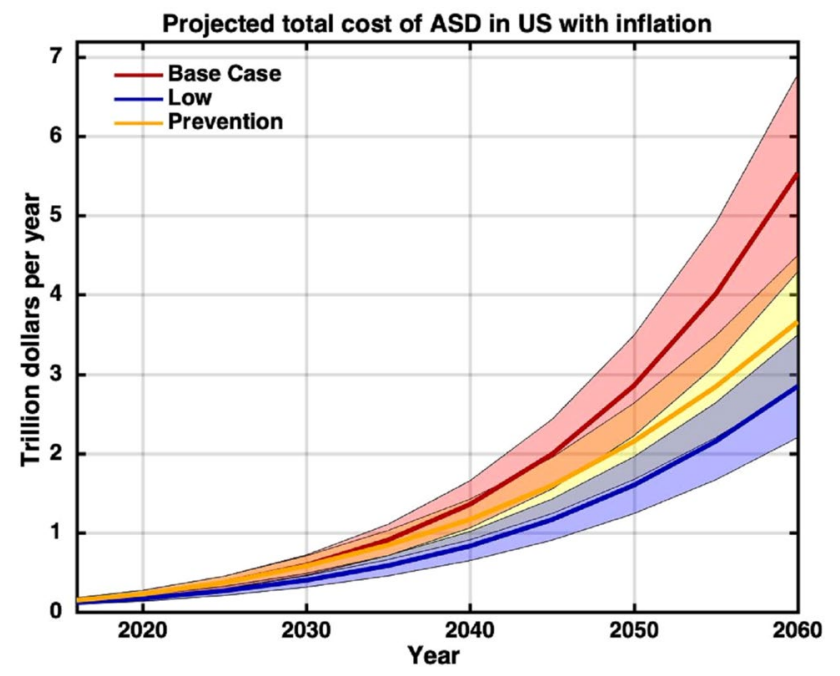

Fig. 3 Total cost of autism in the U.S. from 2016 through 2060, showing three scenarios for future growth in US autism prevalence. Ranges of variability around each scenario reflect uncertainty in the scalars applied to severe ASD prevalence to estimate total (severe + milder) ASD prevalence. The scalars range from 2.1 to 3.5, with the mean value shown as a solid line
When the financial toll of ASD is broken down into cost categories, child-oriented expenses (education, EIBI, and parental productivity loss) account for $54 \%$ of all costs in 2020. Toward the latter half of the future projection, as ASD is assumed to asymptote to a stable value, the adult-dominated costs of non-medical services and individual productivity loss account for an increasing share of the total burden (63\% by 2060). The Low scenario follows a similar pattern, but with lower absolute costs. The Prevention scenario offers an interesting contrast in that education and parental productivity loss diminish, elevating non-medical services and individual productivity to consume $78 \%$ of total costs by 2060 .

Similarly, when broken down into age categories, 67\% of the cost of ASD in the Base Case scenario in 2020 is due to youth age 21 and under, with $42 \%$ of the total cost due to children age 11 and under alone (Fig. 5). This cost breakdown shifts dramatically moving out toward 2060, when adults age 22 and older account for nearly $71 \%$ of all costs. The Low scenario follows a similar pattern, with lower absolute costs. The Prevention scenario again offers a contrast with costs among adults shifting to $91 \%$ of total costs by 2060 .

\section{Discussion}

Previous work on the economic costs of ASD has provided a strong foundation upon which our study is built (Buescher et al., 2014; Cakir et al., 2020; Ganz et al., 2007; Jarbrink et al., 2003, 2007; Knapp et al., 2009; Lavelle et al., 2014;). At the same time, most past studies have focused on different end points and objectives than our study, e.g., estimating the per capita lifetime cost for an individual with ASD (Buescher et al., 2014; Ganz et al., 2007) or estimating the total lifetime country-wide cost of the generational cohort with ASD born between 1990 and 2019 (Cakir et al., 2020). Consequently, direct comparisons of our results to previous studies are often not straightforward, especially when "discounting," i.e., adjusting for the future depreciation of the value of the dollar, is invoked in the lifetime calculations (Buescher et al., 2014; Ganz et al., 2007). Another issue is that the previous literature has focused more attention on the cost per individual than on the population size component
Table 3 Total ASD costs in selected projection years. Unless otherwise noted, all costs are in inflation-adjusted billions of U.S. dollars per year

\begin{tabular}{lcccl}
\hline Year & Base case & Base case (in billion 2018 \$) & Low scenario & Prevention scenario \\
\hline 2016 & $147(116-179)$ & $157(124-191)$ & $118(92-143)$ & $147(116-179)$ \\
2020 & $223(175-271)$ & $209(164-254)$ & $170(133-207)$ & $223(175-271)$ \\
2025 & $370(290-450)$ & $291(228-354)$ & $265(208-323)$ & $370(290-450)$ \\
2030 & $589(461-717)$ & $393(308-478)$ & $399(312-486)$ & $580(454-706)$ \\
2040 & $1357(1059-1654)$ & $655(512-798)$ & $830(646-1014)$ & $1165(908-1421)$ \\
2050 & $2853(2220-3486)$ & $995(776-1215)$ & $1598(1239-1956)$ & $2151(1669-2632)$ \\
2060 & $5535(4291-6779)$ & $1393(1083-1703)$ & $2846(2199-3494)$ & $3660(2822-4498)$ \\
\hline
\end{tabular}


of the calculation. Only recently have comprehensive analyses approached the central question of time trends and the potential for true increases in cost that will accompany rising population prevalence (Cakir et al., 2020; Leigh \& Du, 2015).

The analysis by Leigh and Du (2015) is the most directly comparable to our own, in that it provides annual U.S. cost estimates both for the present day (2015) and projected into the future (2025). Annual cost estimates are probably the most relevant to policy makers, since they predict actual dollar amounts for a given budget year. Like us, Leigh and Du (2015) addressed the implications of rising ASD prevalence, albeit in a single scenario. Our analysis is the first to model annual costs for the entire United States under scenarios that reflect the strong evidence for rising ASD prevalence, based on the best available data, and the consequent future exponential increase in the adult population of individuals with ASD.

Our total cost estimate in 2016 of $\$ 147$ billion dollars is substantially lower than the \$268 (range \$162-367 billion) estimated by Leigh and Du (2015) for 2015 (Table 3). The discrepancy is due largely to Leigh and Du's assumption of historically constant ASD prevalence, which we would argue leads to an overestimate of the current adult population with autism. Even by 2025, as the young adult population with ASD has begun to expand but the older adult population has not yet increased, the Leigh and Du estimate of \$461 billion (range \$276-1011 billion) still exceeds our projection of $\$ 370$ billion (Table 3). The assumption of constant prevalence is not a trivial issue for the cost calculation. It leads to a substantial overestimate of the present-day economic burden, since in our model (also in Cakir et al., 2020) ASD costs are higher for adults than children. Cost analyses that assume constant prevalence thus place a large portion of their total cost estimate on an adult population that does not yet exist. Conversely, as rates of ASD among children have increased far above $1 \%$, cost of disease models that assume constant prevalence (around 1\%) tend to understate the current childhood cost for ASD, even though this underestimate may be masked by the overestimate of the adult population when the total population cost is reported (Leigh $\& \mathrm{Du}, 2015)$.

If, in fact, ASD rates have risen from 1 in 10,000 for individuals born before 1950 to 1 in 2500 for individuals born in the 1980 s to nearly $3 \%$ for the current childhood population, then the implications for the cost burden and its evolving structure over time are staggering. Our two largest ASD cost categories are (indirect) individual productivity loss, which peaks in middle age, followed by direct non-medical services such as residential housing, for which costs rise steadily with age (Table 1). In our calculation, those two categories account for $35 \%$ of total costs around 2020 but increase to nearly $63 \%$ of total costs by 2060 , as the adult population with ASD expands (Fig. 4). Similarly, adults 22 and over account for only $33 \%$ of total ASD costs in 2020, but the adult share increases to $71 \%$ by 2060 (Fig. 5). At least one federal funding source, the Social Security Disabilities Insurance (SSDI) Program provides emerging evidence of this trend. The Social Security Administration issues an Annual Statistical Report on the SSDI Program. This report has long included a count of adult beneficiaries (ages 18-64) by diagnostic group. Before 2010, there was no listing of autistic beneficiaries. In the 2010 report, autistic disorder was included for the first time and in the years since its inclusion, the count of adult autistic SSDI beneficiaries has increased at an annual rate of $14 \%$ : from 72,449 in the 2010 report to 232,003 in the 2019 report (SSA, 2011, 2020).

Year 2016 is the earliest year of our annual cost calculation. Thus, we cannot compare our results directly to Cakir et al. (2020), who estimated a lifetime cost of $\$ 7$ trillion for the cohorts with ASD born between 1990 and 2019. However, we can compare our annual present-day costs based on Table 1 to a summation of the corresponding costs assumed by Cakir et al. Here both our and Cakir et al.'s study assumed the cost category structure defined by Buescher et al. (2014). Our estimates are considerably larger than Cakir et al. who assumed (using 2019 dollars) a cost of $\$ 49.9$ thousand for children 3-17 and \$83.4 thousand for adults age 18+. Our costs, which are broken down into finer age categories, are similar for children 3-21 (\$48-56 thousand/year) but substantially higher for adults, especially during the peak earning years of age 32-61 when our total cost estimates range from $\$ 105-116$ thousand/year. The difference is due mainly to our assumption of substantially higher individual productivity loss and also higher direct non-medical costs for adults with ASD.

In comparison to Buescher et al. (2014), our annual costs tend to be smaller for children but larger for adults. (Note: Leigh and $\mathrm{Du}$ (2015) directly adopted Buescher et al.'s costs, inflated to 2015 dollars.) Using 2011 dollars, Buescher et al. assumed, for those with severe autism (which they defined based on co-occurring intellectual disability [ID]), a total cost of \$107.9 thousand/year for 0-5 year-olds, $\$ 86.1$ thousand/year for 6-17 year-olds and $\$ 88.0$ thousand/year for adults age $18+$. Total costs for milder ASD (i.e., without ID) were assumed to be about $40 \%$ lower. The high values for children were due to Buescher et al.'s assumption of weighty values for special education, including early intervention, and to a lesser extent to their assumption of direct medical costs of up to $\$ 13$ thousand/yr. This latter assumption has been criticized as being more than a factor of 2 too high (Zuvekis et al., 2020). EIBI, while a significant cost for children with ASD, is difficult to estimate with available sources. Buescher et al.'s large annual cost estimates for young children with ASD assume near universal adoption of EIBI from birth. For our model, we adopt similar costs for 


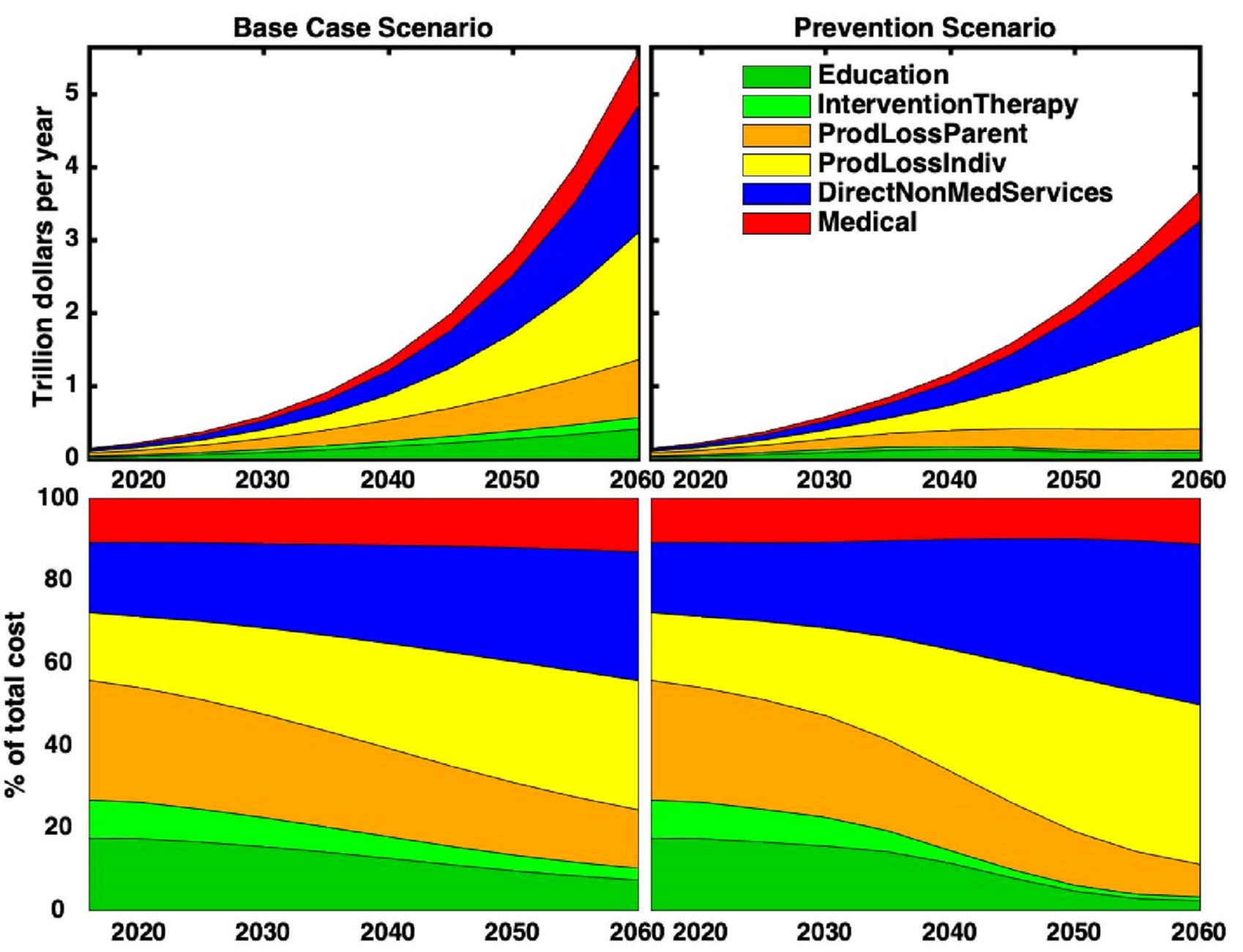

Fig. 4 Total cost of autism in the U.S. from 2016 through 2060, broken down by cost category, comparing Base Case (left) and Prevention (right) scenarios, assuming a mean total/severe ASD ratio of 2.8

(mean of full 2.1-3.5 range shown in Fig. 3). Top row shows costs in absolute inflation-adjusted dollars. Bottom row shows costs as percent of total

a full-time EIBI program but assume that EIBI begins later, is utilized less frequently, and is often less than full-time.

In contrast to their likely overestimate of children's ASD costs, Buescher et al. almost certainly underestimated adult ASD costs, primarily due to the exceptionally low value of $\$ 10,718 / y r$ assumed for individual productivity loss (both with or without co-occurring ID). Even when inflated to 2018 dollars, this is far lower than the mean men's salary of $\sim \$ 76,000 / y r$ during peak earning years in middle age (Davenport et al., 2019). The reason for the low value is that Buescher assumed a high employment rate for all individuals with ASD, regardless of ID status. In contrast, we assume an employment rate of $0 \%$ and $30 \%$ of those with severe and mild ASD, respectively. Buescher et al. relied on estimates of ASD workforce participation that focused on HFA and Asperger's adults and equated participation in work with productivity (David Mandell, personal communication 2018). By contrast, we define full-time, unsupported employment, which is generally quite low in ASD adults, as a more realistic standard for productivity.

The uncertainty in our calculations is defined by our range of prevalence scenarios and by the scaling factors we apply to convert severe autism into total ASD. We implicitly assume that the uncertainties in the census projections of overall population and in the individual cost category prices are subsumed in those two larger primary uncertainties. Previous studies have made similar assumptions (e.g., Leigh $\&$ Du, 2015). With respect to the total:severe ASD scaling factors, our lower bound (2.1) is based on comparing ADDM data, which are in some respects the most authoritative, to the comparable California DDS snapshot (on which our severe ASD projections are based), but likely left out many cases of autism that were previously considered Asperger's cases. Our higher bound (3.5) is based on comparing the midpoint NCHS surveys of children to their California DDS equivalents: the NCHS surveys are less rigorous and 


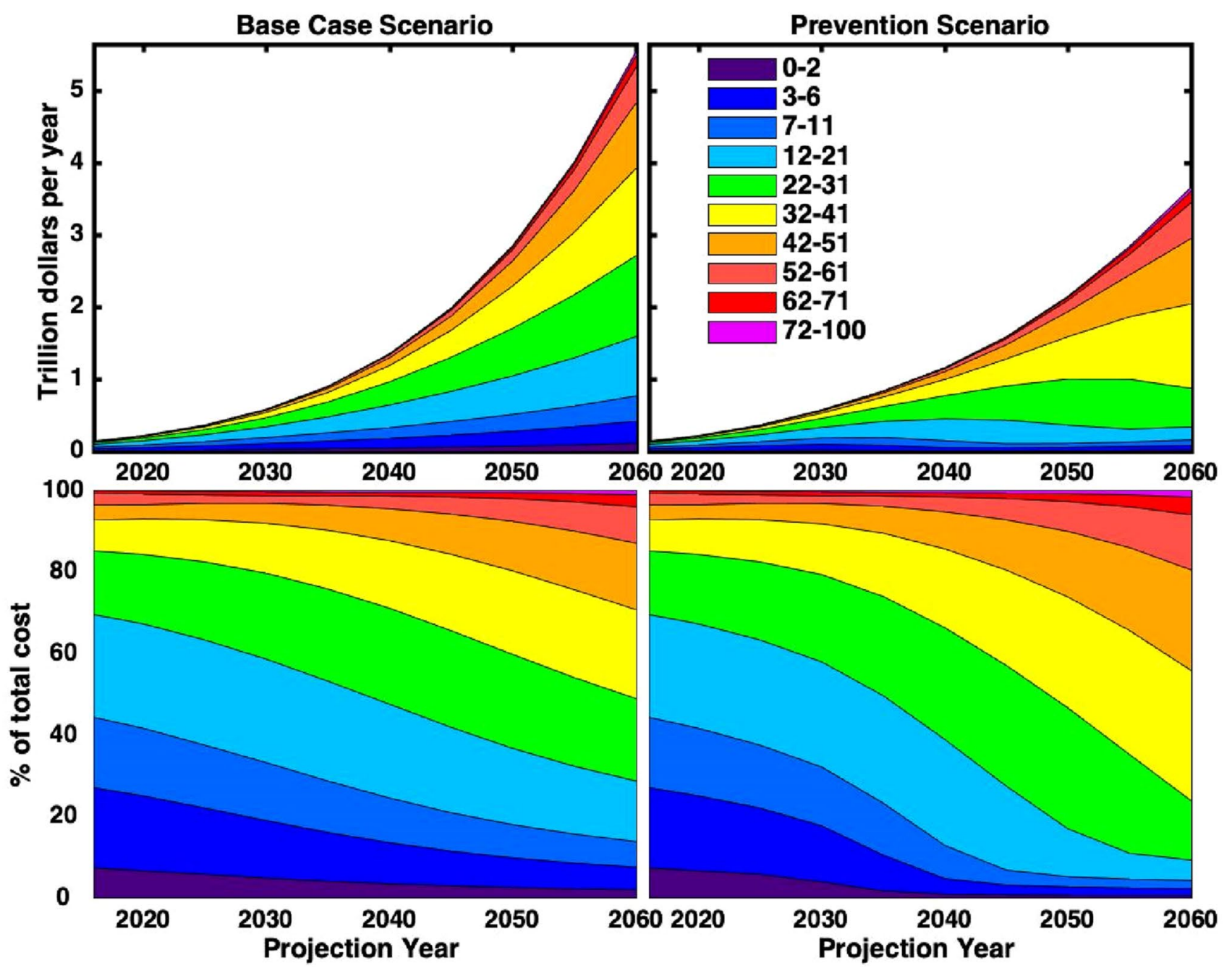

Fig. 5 Total cost of autism in the U.S. from 2016 through 2060, broken down by age group, comparing Base Case (left) and Prevention (right) scenarios, assuming a mean total/severe ASD ratio of 2.8. Top

row shows costs in absolute inflation-adjusted dollars. Bottom row shows costs as percent of total

possibly subject to overstatement, but likely include more higher functioning individuals. We made the further assumption that the growth in prevalence of total ASD will continue to parallel the growth in severe ASD cases, with a constant proportionality of 2.1-3.5. This assumption involves substantial uncertainty but was made due to a lack of information for a better assumption. Other surveys that report both broad and narrow ASD rates (Bertrand et al., 2001; Burd et al., 1987; Gurney et al., 2003; Treffert, 1970) have total:severe ratios that range from 1.1 to 9.2 but are either more variable in their approach or more restricted in geographic coverage.

Our assumptions about how ASD prevalence will project into the future are the single largest uncertainty in our calculation. The Base Case scenario is our best guess case because it is based on the most recently available trend data from California DDS from 2020. The Low scenario was included as a conservative case with the rationale that after 2014 CDDS had switched to the DSM-5 criteria and thus may have expanded to include milder ASD cases in more recent years. Both the Base Case and Low scenarios project future growth as an asymptotic logistic function, or $\mathrm{S}$ curve, based on the assumption that the growth in $R$ cannot continue indefinitely, either because the susceptible fraction of the population at some point will saturate or because efforts to identify causal drivers will accelerate to a new level of urgency as severe autism prevalence approaches $2.9 \%$ (implying total ASD prevalence of up to $10.0 \%$ ). These assumptions might be regarded as conservative or optimistic given that current total ASD levels of about 3\% have been met with complacency (e.g., Zablotsky et al., 2017) and that ASD currently appears to be growing at a steep ongoing rate in the 2020 California DDS data (Fig. 1). In these data, it is notable that ASD prevalence among 4 year-olds in the 2016 
birth cohort already exceeds that among 5 year-olds born the previous year (Fig. 1). This feature has not been seen in California DDS data since the 2010 cohort and likely portends a steeper uptick in the prevalence when the 2016 cohort is fully diagnosed (Nevison et al., 2018).

The enormous future costs of ASD projected by our model (Fig. 3) raise the logical question, can these costs be mitigated or avoided? Leigh and Du (2015) included an early intervention scenario in which intensive ABA therapy was assumed to reduce the future costs of ASD by a factor of two among affected adults, who were assumed to have milder symptoms and thus require less care. This scenario led to a savings of $\$ 28$ billion by 2025 relative to the Leigh and Du (2015) base case. We opted for a prevention scenario to explore the possibility of future mitigation, rather than an intervention scenario, due to the lack of empirical evidence that early intervention actually reduces adult costs by a factor of 2 (Camarata, 2014; Fein et al., 2013; Rogers et al., 2012). In contrast, the reduced prevalence of $0.6 \%$ severe ASD (corresponding to 1.3-2.1\% total ASD with our assumed total:severe scaling factors) used in our Prevention scenario is based on real rates observed among wealthy white and Asian children in the California DDS dataset (Nevison \& Parker, 2020). Severe ASD prevalence has flattened and even declined among these children since birth year 2000, suggesting that wealthy parents have been making changes that effectively lower their children's risk of developing ASD. The Prevention scenario assumes that these parental strategies and opportunities already used by wealthy parents to lower their children's risk of ASD can be identified and made available rapidly to lower income children and ethnic minorities, who are currently experiencing the most rapid growth in ASD prevalence (Nevison \& Zahorodny, 2019; Yuan et al., 2021).

Even under the Prevention scenario, the cost of ASD soars to $\$ 3.7 \pm 0.8$ trillion annually by 2060 , a $33 \%$ reduction from our standard Base Case scenario price tag of $5.5 \pm 1.2$ trillion, but still a steep cost. This is because the Prevention scenario initially follows the trajectory of the Base Case scenario and the demographic momentum of the large ASD population born over the last three decades still results in large total costs by 2060 . The asymptotic rate of $0.6 \%$ severe ASD assumed in the Prevention scenario is still notably high compared to historical levels, which were $0.06 \%$ in 1980 (Nevison et al., 2018). If a more dramatic reduction is assumed, e.g., to $0.06 \%$ severe ASD by 2040 (following the same time trajectory of our current Prevention scenario), the total cost of ASD drops to $\$ 3.2$ trillion/year by 2060, again still an enormous cost due to demographic momentum, but a savings of $\$ 2.3$ trillion/year over the current business-asusual Base Case scenario in 2060.
McDonald and Paul (2010) in a study for the U.S. Environmental Protection Agency find that autism rates in the U.S. began to increase sharply in 1987. At that time, the average age of mothers in the U.S. was 26 years old (Matthews \& Hamilton, 2002). The average age of retirement in the U.S. is 64 (U.S. Census Bureau, 2017) and average life expectancy in the U.S. in 2018 is 78.7 years (Xu et al., 2018). Over the last three decades of rising autism prevalence, parents incurred a significant proportion of costs (especially housing but also increased costs for medical care and supportive services). However, the first large cohort of autism parents will begin to retire in 2025 . When that happens, autism costs that were formerly borne by parents will shift onto local, state, and federal government. The first large cohort of autism parents will die on average around 2040. At that point, most of the costs of autism (hundreds of billions of dollars annually) will shift permanently onto the public sector.

Our analysis sheds new light on important, underexplored policy issues that will inevitably arise from this shift. Many, and potentially severe, new constraints on resources will arise should future demands play out as our scenarios suggest, including (but not limited to) adult residential accommodation and caregiver support, not to mention the broader effect on the economy. Specifically, as the adult ASD population grows and ages, where will their residential placements come from as their parents grow old and die? As increasing portions of the adult population become disabled and dependent, where will the caregiving workforce that must replace parental caregivers come from and how will their support work be funded? With a large proportion of the productive-age workforce unable to contribute to our economy, how will the America economy suffer as a whole?

As of this writing, governments at all levels in the U.S. have difficulty even acknowledging the size and scope of the growth in autism. Even though the costs of autism are on par with or even exceed the largest line items in the budget there is currently no plan to meet this enormous fiscal challenge. In the absence of a comprehensive plan to either raise revenue or prevent autism through mitigation of causal factors, the costs of autism represent a serious threat to the economic future of the U.S.

\section{Conclusion}

An increasing volume of research has pointed to the high and rising economic burden of ASD in the United States. But the weight of previous cost of disease assessments have been based on an assumption of constant prevalence and are therefore misleading for purposes of policy, provision of care and intensity of prevention efforts. Our analysis 
combines dynamic birth year prevalence-based population forecasts with updated life cycle cost estimates to compute an alarming set of projections for the economic impact of what some have described as the autism "tsunami." Our model projects a total population-wide ASD cost in the U.S. of $\$ 5.54$ (4.29-6.78) trillion/year by 2060, accounting for inflation, with potential savings of $\$ 1.9$ trillion/year with pursuit of ASD prevention. We believe these projections work against the temptation to normalize recent trends in ASD prevalence. Rather, they reinforce the need to address rising autism prevalence as more than just an urgent public health concern but also as a policy question with respect to where resources will come from and how to mitigate and prevent the worst case scenarios.

\section{Appendix}

\section{Autism Cost Model, Details of Calculation}

Our base calculation focuses on the cost of the more severe end of the autism spectrum, as defined based on the California Department of Developmental Services (CDDS) caseload, inflate $($ optional term $)=$ rate of inflation relative to base year 2018, compounded to each of the projection years from 2020 to 2060, distinguishing between productivity, medical and nonmedical categories.

Equation 3 permits the isolation of any individual index or set of combined indices by integrating over the remaining indices. For example, our main results are presented as a function of scenario and projection year, by integrating over the ibyr and icat indices,

$$
\begin{aligned}
& \cos t \_s e v e r e(i p y r, i s c)=\sum_{i b y r=1931}^{2060} \text { Rasd_CDDS }(\text { ibyr }, \text { isc }) \\
& * \text { census_pop }(\text { iage }, \text { ipyr }) * \sum_{i c a t}^{6}\left\{\cos t c a t \_C D D S(\text { iage }, \text { icat })\right. \\
& * \inf \text { late }(\text { ipry, icat })\}
\end{aligned}
$$

In these calculations, iage, ipyr and ibyr are interrelated through Eq. 5,

ibyr $=i p y r-i a g e$

In practice, this means that the appropriate matching ibyr index for costcat_CDDS and census_pop, which are

cost_severe $(i b y r$, ipyr, isc, icat $)=$ Rasd_CDDS $($ ibyr, isc $) *$ census_pop $($ iage, ipyr $) *$ costcat_CDDS $($ iage, icat $) *$ inflate $($ ipyr, icat $)$

where,

cost_severe $=$ the cost of severe autism.

Rasd_CDDS = autism prevalence from California DDS (CDDS) in \%.

census_pop $=$ age-resolved census population for each of 10 projection years.

costcat_CDDS $=$ dollar cost of severe autism per individual per year for each of 5 cost categories. functions of iage, is identified within the ibyr loop and substituted for iage in Eqs. 3, 4 and 6 below.

Since, as described below, severe autism accounts for only about one half to one third of all ASD, we estimate the additional cost of milder ASD by multiplying Rasd_CDDS by a range of scalars and applying a variant of Eq. 3,

cost_milder(ibyr,ipyr, isc, icat $)=$ Rasd_CDDS(ibyr, isc $) *$ scale_factor $*$

census_pop $($ iage, ipyr) $*$ costcat_milder(iage, icat $) *$ inflation $($ ipyr, icat $)$,

$i b y r=$ birth year, extending from 1931 to 2060.

$i p y r=$ projection year, indexed in 2016 and at each 5 year milepost from 2020-2060.

$i s c=3$ different future scenarios for U.S. autism prevalence through 2060.

icat $=$ index of 6 cost categories.

iage $=$ index of age of cases in a given projection year, resolved annually from $0-100$ years old. where,

cost_milder $=$ the cost of milder ASD.

scale_factor $=$ a range of scalars (1.1-2.5) reflecting the ratio of milder ASD to the more severe forms of ASD served by CDDS.

costcat_milder $=$ dollar cost of milder autism per individual per year for each of six cost categories. 
Similar to cost_severe, any individual or set of combined indices can be isolated for cost_milder by integrating over the remaining indices. The total cost of ASD is then,

cost_total $=$ cost_severe + cost_milder

Supplementary Information The online version contains supplementary material available at https://doi.org/10.1007/s10803-021-05120-7.

Author Contributions MB conceived of the study, wrote the Introduction and computed the inflation adjustments. MB and TR researched and compiled the cost category estimates. CN performed the model calculations and wrote the Results. All authors wrote parts of the Methods and Discussion and approved the final manuscript.

Funding None of the authors received specific funding for this work.

\section{Declarations}

Conflict of interest $\mathrm{CN}$ and TR declare that the research was conducted in the absence of any commercial or financial relationships that could be construed as a potential conflict of interest. MB is the CFO of the Holland Center, a public and private insurance-funded day treatment program serving children and young adults with autism.

Open Access This article is licensed under a Creative Commons Attribution 4.0 International License, which permits use, sharing, adaptation, distribution and reproduction in any medium or format, as long as you give appropriate credit to the original author(s) and the source, provide a link to the Creative Commons licence, and indicate if changes were made. The images or other third party material in this article are included in the article's Creative Commons licence, unless indicated otherwise in a credit line to the material. If material is not included in the article's Creative Commons licence and your intended use is not permitted by statutory regulation or exceeds the permitted use, you will need to obtain permission directly from the copyright holder. To view a copy of this licence, visit http://creativecommons.org/licenses/by/4.0/.

\section{References}

American Psychiatric Association. (1994). Diagnostic and statistical manual of mental disorders (4th ed.). American Psychiatric Association.

American Psychiatric Association. (2013). Diagnostic and statistical manual of mental disorders (5th ed.). American Psychiatric Association.

Bertrand, J., Mars, A., Boyle, C., Bove, F., Yeargin-Allsopp, M., \& Decoufle, P. (2001). Prevalence of autism in a United States population: The Brick Township, New Jersey, investigation. Pediatrics, 108(5), 1155-1161. https://doi.org/10.1542/peds.108.5.1155 PMID: 11694696

Blaxill, M. F. (2004). What's going on? The question of time trends in autism. Public Health Reports, 119(6), 536-551. https://doi.org/10. 1016/j.phr.2004.09.003 PMID: 15504445.

Blumberg, S. J., Bramlett, M. D., Kogan, M. D., Schieve, L. A., Jones, J. R., \& Lu, M. C. (2013). Changes in prevalence of parent-reported autism spectrum disorder in school-aged US children: 2007 to 2011-2012. National Health Statistic Report, 65, 1-11. PMID: 24988818 .
British Journal of Family Medicine, (2014). Autism most costly medical condition in UK, report claims. Retrieved from https://www.bjfm. co.uk/autism-most-costly-medical-condition-in-uk-report-claims

Buescher, A. V., Cidav, Z., Knapp, M., \& Mandell, D. S. (2014). Costs of autism spectrum disorders in the United Kingdom and the United States. JAMA Pediatrics, 8(8), 721-728. https://doi.org/10.1001/ jamapediatrics.2014.210 PMID: 24911948.

Burd, L., Fisher, W., \& Kerbeshian, J. (1987). A prevalence study of pervasive developmental disorders in North Dakota. Journal of the American Academy of Child and Adolescent Psychiatry, 26(5), 700-703. https://doi.org/10.1097/00004583-198709000-00014 PMID: 3499432.

Butter, E. M., Wynn, J., \& Mulick, J. A. (2003). Early intervention critical to autism treatment. Pediatric Annals, 32(10), 677-684. https:// doi.org/10.3928/0090-4481-20031001-09 PMID: 14606218.

Byrd, R. S., Sage, A. C., Keyzer, J., Shefelbine, R., Gee, K., Enders, K., et al. Report to the Legislature on the principal findings from the epidemiology of autism in California: A comprehensive pilot study. Davis (CA): MIND Institute; 2002 Oct 17

Cakir, J., Frye, R. E., \& Walker, S. J. (2020). The lifetime social cost of autism: 1990-2029. Research in Autism Spectrum Disorders, 72, 101502. https://doi.org/10.1016/j.rasd.2019.101502

California Department of Developmental Services. Changes in the population of persons with autism and pervasive developmental disorders in California's developmental services system: 1987 through 1998: A report to the Legislature. Sacramento: California Health and Human Services Agency, Department of Developmental Services; 1999.

California Department of Developmental Services. Autistic spectrum disorders: changes in the California caseload: an update: 1999 through 2002. Sacramento: California Health and Human Services Agency, Department of Developmental Services; 2003.

CA Department of Developmental Services (2019). Fact book, Fiscal year 2017-2018, Sixteenth Edition. DDS Information Technology Division, July 2019. Department of Developmental Services, Sacramento CA. Retrieved from https://www.dds.ca.gov/wp-content/ uploads/2019/11/DDS_FactBook_2019.pdf

Camarata, S. (2014). Early identification and early intervention in autism spectrum disorders: Accurate and effective? International Journal of Speech-Language Pathology, 1, 1-10. https://doi.org/10.3109/ 17549507.2013.858773

Centers for Disease Control and Prevention. (2007). Prevalence of autism spectrum disorders-autism and developmental disabilities monitoring network, 14 sites, United States, 2002. MMWR Surveill Summ, 56(1), 12-28.

Centers for Disease Control and Prevention. (2009). Prevalence of autism spectrum disorders-Autism and Developmental Disabilities Monitoring Network, United States, 2006. MMWR Surveill Summ, 58(10), 1-20.

Centers for Disease Control and Prevention. (2012). Prevalence of autism spectrum disorders-Autism and Developmental Disabilities Monitoring Network, 14 sites, United States, 2008. MMWR Surveill Summ, 61(3), 1-19.

Centers for Disease Control and Prevention. (2020). Prevalence of Autism Spectrum Disorder Among Children Aged 8 Years Autism and Developmental Disabilities Monitoring Network, 11 Sites, United States, 2016. MMWR Surveill Summ, 69(4), 1-12.

Centers for Disease Control and Prevention April 2000, prevalence of autism in Brick Township, New Jersey, 1998: Community Report. Retrieved from https://www.cdc.gov/ncbddd/developmentaldisabil ities/documents/brick-report.pdf.

Centers for Disease Control and Prevention. (2007). Prevalence of autism spectrum disorders-autism and developmental disabilities monitoring network, six sites, United States, 2000. Morbidity and Mortality Weekly Report, 56(SS01), 1-11. 
Centers for Disease Control and Prevention. (2014). Prevalence of autism spectrum disorder among children aged 8 years - autism and developmental disabilities monitoring network, 11 sites, United States, 2010". Morbidity and Mortality Weekly Report, 63(2), 1-21.

Centers for Disease Control and Prevention. (2016). Prevalence and characteristics of autism spectrum disorder among children aged 8 years-autism and developmental disabilities monitoring network, 11 Sites, United States, 2012. Morbidity and Mortality Weekly Report, 65(3), 1-23.

Centers for Disease Control and Prevention. (2018). Prevalence and characteristics of autism spectrum disorder among children aged 8 Years-autism and developmental disabilities monitoring network , 11 Sites , United States, 2014.” Morbidity and Mortality Weekly Report 67 (6).

Chambers, J. G., Parrish, T. B., \& Harr, J. J. (2002). What are we spending on special education services in the United States, 1999-2000? Report. Special education expenditure project (SEEP) Washington, DC: American Institutes for Research in the behavioral sciences, Palo Alto, CA. Center for Special Education Finance. Special Education Programs (ED/OSERS). Retrieved from https://files.eric.ed. gov/fulltext/ED471888.pdf

Chambers, J. G., Shkolnik, J., \& Perez, M. (2003). Special education expenditure report: Total expenditures for students with disabilities, 1999-2000: Spending variation by disability. Palo Alto, CA: American Institutes for Research.

Chasson, G. S., Harris, G. E., \& Neely, W. J. (2007). Cost comparison of early intensive behavioral intervention and special education for children with autism. Journal of Child and Family Studies, 16, 401-413. https://doi.org/10.1007/s10826-006-9094-1

Cidav, Z., Marcus, S. C., \& Mandell, D. S. (2012). Implications of childhood autism for parental employment and earnings. Pediatrics, 129(4), 617-623. https://doi.org/10.1542/peds.2011-2700 PMID: 22430453.

Cidav, Z., Munson, J., Estes, A., Dawson, G., Rogers, S., \& Mandell, D. (2017). Cost offset associated with early start Denver model for children with autism. Journal of the American Academy of Child and Adolescent Psychiatry, 9, 777-783. https://doi.org/10.1016/j. jaac.2017.06.007 PMID: 28838582.

Davenport, S., Weaver, A., \& Caverly, M. (2019). Economic impact of non-medical opioid use in the United States: Annual estimates and projections for 2015 through 2019. Society of Actuaries.

Eaves, L. C., \& Ho, H. H. (2008). Young adult outcome of autism spectrum disorders. Journal of Autism and Developmental Disorders, 38(4), 739-747. https://doi.org/10.1007/s10803-007-0441-x PMID: 17764027.

Farley, M., Cottle, K. J., Bilder, D., Viskochil, J., Coon, H., \& McMahon, W. (2018). Mid-life social outcomes for a population-based sample of adults with ASD. Autism Research, 11(1), 142-152. https://doi. org/10.1002/aur.1897 PMID: 29266823.

Fein, D., Barton, M., Eigsti, I.-M., Kelley, E., Naigles, L., Schultz, R. T., Stevens, M., Helt, M., Orinstein, A., Rosenthal, M., Troyb, E., \& Tyson, K. (2013). Optimal outcome in individuals with a history of autism. Journal of Child Psychology and Psychiatry, 54(2), 195-205. https://doi.org/10.1111/jcpp.12037

Ganz, M. L. (2007). The lifetime distribution of the incremental societal costs of autism. Archives of Pediatrics and Adolescent Medicine, 161(4), 343-349. https://doi.org/10.1001/archpedi.161.4.343 PMID: 17404130.

Gurney, J. G., Fritz, M. S., Ness, K. K., Sievers, P., Newschaffer, C. J., \& Shapiro, E. G. (2003). Analysis of prevalence trends of autism spectrum disorder in Minnesota. Archives of Pediatrics and Adolescent Medicine, 157(7), 622-627. https://doi.org/10.1001/archp edi.157.7.622 PMID: 12860781.

Jacobson, J. W., Mulick, J. A., \& Green, G. (1998). Cost-benefit estimates for early intensive behavioral intervention for young children with autism-general model and single state case. Behavioral
Interventions, 13, 201-226. https://doi.org/10.1002/(SICI) 1099-078X(199811)

Järbrink, K., McCrone, P., Fombonne, E., Zandén, H., \& Knapp, M. (2007). Cost-impact of young adults with high-functioning autistic spectrum disorder. Research in Developmental Disabilities, 28(1), 94-104. https://doi.org/10.1016/j.ridd.2005.11.002 PMID: 16551499 .

Järbrink, K., Fombonne, E., \& Knapp, M. (2003). Measuring the parental, service and cost impacts of children with autistic spectrum disorder: A pilot study. Journal of Autism and Developmental Disorders, 33(4), 395-402. https://doi.org/10.1023/a:1025058711465 PMID: 12959418.

Järbrink, K. (2007). The economic consequences of autistic spectrum disorder among children in a Swedish municipality. Autism, 11(5), 453-463. https://doi.org/10.1177/1362361307079602 PMID: 17942458.

Jennes-Coussens, M., Magill-Evans, J., \& Koning, C. (2006). The quality of life of young men with asperger syndrome: A brief report. Autism, 10(4), 403-414. https://doi.org/10.1177/1362361306 064432 PMID: 16908482.

Knapp, M., Romeo, R., \& Beecham, J. (2009). Economic cost of autism in the UK. Autism, 13(3), 317-336. https://doi.org/10.1177/13623 61309104246 PMID: 19369391.

Kogan, M. D., Blumberg, S. J., Schieve, L. A., Boyle, C. A., Perrin, J. M., Ghandour, R. M., Singh, G. K., Strickland, B. B., Trevathan, E., \& van Dyck, P. C. (2009). Prevalence of parent-reported diagnosis of autism spectrum disorder among children in the US, 2007. Pediatrics, 124(5), 1395-1403. https://doi.org/10.1542/peds.2009-1522 PMID: 19805460.

Kogan, M. D., Vladutiu, C. J., Schieve, L. A., Ghandour, R. M., Blumberg, S. J., Zablotsky, B., Perrin, J. M., Shattuck, P., Kuhlthau, K. A., Harwood, R. L., \& Lu, M. C. (2018). The Prevalence of parentreported autism spectrum disorder among US children. Pediatrics, 142(6), e20174161. https://doi.org/10.1542/peds.2017-4161 PMID: 30478241.

Larsen, F. W., \& Mouridsen, S. E. (1997). The outcome in children with childhood autism and Asperger syndrome originally diagnosed as psychotic. A 30-year follow-up study of subjects hospitalized as children. European Child Adolescent Psychiatry, 6(4), 181-190. https://doi.org/10.1007/BF00539924 PMID: 9442996.

Lavelle, T. A., Weinstein, M. C., Newhouse, J. P., Munir, K., Kuhlthau, K. A., \& Prosser, L. A. (2014). Economic burden of childhood autism spectrum disorders. Pediatrics, 133(3), e520-e529. https:// doi.org/10.1542/peds.2013-0763 PMID: 24515505.

Leigh, J. P., \& Du, J. (2015). Brief report: Forecasting the economic burden of autism in 2015 and 2025 in the United States. Journal of Autism and Developmental Disorders, 45(12), 4135-4139. https:// doi.org/10.1007/s10803-015-2521-7 PMID: 26183723.

Leigh, J. P., Grosse, S. D., Cassady, D., Melnikow, J., \& Hertz-Picciotto, I. (2016). Spending by California's Department of Developmental Services for persons with autism across demographic and expenditure categories. PLOS ONE, 11(3), e0151970. https://doi.org/10. 1371/journal.pone.0151970

Lingam, R., Simmons, A., Andrews, N., Miller, E., Stowe, J., \& Taylor, B. (2003). Prevalence of autism and parentally reported triggers in a north east London population. Archives of Disease in Childhood, 88(8), 666-670. https://doi.org/10.1136/adc.88.8.666 PMID: 12876158.

MacFarlane, J. R., \& Kanaya, T. (2009). What does it mean to be autistic? Inter-state variation in special education criteria for autism services. Journal of Child and Family Studies, 18(6), 662.

Martin, J. A., Hamilton, B. E., Osterman, M. J. K., Driscoll, A. K. Births: Final Data for 2019. National Vital Statistics Reports; vol 70 no 2. Hyattsville, MD: National Center for Health Statistics. 2021. https:// dx.doi.org/https://doi.org/10.15620/cdc:100472. 
Mathews TJ, Hamilton BE. Mean age of mother, 1970-2000. National vital statistics reports; vol 51 no 1. Hyattsville, Maryland: National Center for Health Statistics. 2002.

Mawhood, L., \& Howlin, P. (1999). The outcome of a supported employment scheme for high-functioning adults with autism or asperger syndrome. Autism, 3(3), 229-254. https://doi.org/10.1177/13623 61399003003003

McDonald, M. E., \& Paul, J. F. (2010). Timing of increased autistic disorder cumulative incidence. Environmental Science and Technology, 44(6), 2112-2118. https://doi.org/10.1021/es902057k PMID: 20158232.

Mitroulaki, S., Serdari, A., Tripsianis, G., Gundelfinger, R., Arvaniti, A., Vorvolakos, T., \& Samakouri, M. (2020 ). First alarm and time of diagnosis in autism spectrum disorders. Comprehensive Child and Adolescent Nursing, 22, 1-17. https://doi.org/10.1080/24694193. 2020.1834013 PMID: 33090020.

Nevison, C., \& Parker, W. (2020a). California autism prevalence by county and race/ethnicity: Declining trends among wealthy whites. Journal of Autism and Developmental Disorders, 50(11), 4011-4021. https://doi.org/10.1007/s10803-020-04460-0 PMID: 32193763.

Nevison, C., Blaxill, M., \& Zahorodny, W. (2018). California autism prevalence trends from 1931 to 2014 and comparison to national ASD Data from IDEA and ADDM. Journal of Autism and Developmental Disorders, 48(12), 4103-4117. https://doi.org/10.1007/ s10803-018-3670-2 PMID: 29974300.

Nevison, C., \& Zahorodny, W. (2019). Race/ethnicity-resolved time trends in United States ASD prevalence estimates from IDEA and ADDM. Journal of Autism and Developmental Disorders, 49(12), 4721-4730. https://doi.org/10.1007/s10803-019-04188-6 PMID: 31435818 .

Newschaffer, C. J., Falb, M. D., \& Gurney, J. G. (2005). National autism prevalence trends from United States special education data. Pediatrics, 115(3), e277-e282. https://doi.org/10.1542/peds. 2004-1958 PMID: 15741352

Ohl, A., Grice Sheff, M., Small, S., Nguyen, J., Paskor, K., \& Zanjirian, A. (2017). Predictors of employment status among adults with Autism Spectrum Disorder. Work, 56(2), 345-355. https://doi.org/ 10.3233/WOR-172492 PMID: 28211841.

Petek, G., Overview of special education in California, Legislative Analyst's Office, Retrieved Nov. 6, 2019, from https://lao.ca.gov/ reports/2019/4110/overview-spec-ed-110619.pdf

Ritvo, E. R., Freeman, B. J., Pingree, C., Mason-Brothers, A., Jorde, L., Jenson, W. R., McMahon, W. M., Petersen, P. B., Mo, A., \& Ritvo, A. (1989). The UCLA-University of Utah epidemiologic survey of autism: Prevalence. American Journal of Psychiatry, 146(2), 194-199. https://doi.org/10.1176/ajp.146.2.194 PMID: 2783539.

Rogers, S. J., Estes, A., Lord, C., Vismara, L., Winter, J., Fitzpatrick, A., Guo, M., \& Dawson, G. (2012). Effects of a brief Early Start Denver model (ESDM)-based parent intervention on toddlers at risk for autism spectrum disorders: A randomized controlled trial. Journal of the American Academy of Child and Adolescent Psychiatry, 51(10), 1052-1065. https://doi.org/10.1016/j.jaac.2012. 08.003

Rogers, T. (2019). The Political Economy of Autism. Doctoral thesis. University of Sydney, The Faculty of Arts and Social Sciences, School of Social and Political Sciences, Department of Political Economy. Retrieved from https://ses.library.usyd.edu.au/bitst ream/handle/2123/20198/Rogers_T_thesis.pdf

Rogge, N., \& Janssen, J. (2019). The economic costs of autism spectrum disorder: A literature review. Journal of Autism and Developmental Disorders, 49(7), 2873-2900. https://doi.org/10.1007/ s10803-019-04014-z PMID: 30976961.

Roux, A. M., Shattuck, P. T., Cooper, B. P., Anderson, K. A., Wagner, M., \& Narendorf, S. C. (2013). Postsecondary employment experiences among young adults with an autism spectrum disorder.
Journal of the American Academy of Child and Adolescent Psychiatry, 52(9), 931-939. https://doi.org/10.1016/j.jaac.2013.05. 019 PMID: 23972695.

Rumsey, J. M., Rapoport, J. L., \& Sceery, W. R. (1985). Autistic children as adults: Psychiatric, social, and behavioral outcomes. $J$ Am Acad Child Psychiatry., 24(4), 465-473. https://doi.org/10.1016/ s0002-7138(09)60566-5 PMID: 4019976.

Sallows, G. O., \& Graupner, T. D. (2005). Intensive behavioral treatment for children with autism: Four-year outcome and predictors. American Journal of Mental Retardation, 110(6), 417-438. https://doi.org/10.1352/0895-8017(2005)110 PMID: 16212446.

Shattuck, P. T., Narendorf, S. C., Cooper, B., Sterzing, P. R., Wagner, M., \& Taylor, J. L. (2012). Postsecondary education and employment among youth with an autism spectrum disorder. Pediatrics, 129(6), 1042-1049. https://doi.org/10.1542/peds.2011-2864 PMID: 22585766

Shenouda, J. \& Zahorodny, W. Higher than expected ASD prevalence in Toms River, New Jersey in 2016. International Society for Autism Research (INSAR), 2021 virtual meeting, May 3-7, 2021.

Shimabukuro, T. T., Grosse, S. D., \& Rice, C. (2008 Mar). Medical expenditures for children with an autism spectrum disorder in a privately insured population. Journal of Autism and Developmental Disorders, 38(3), 546-552. https://doi.org/10.1007/s10803007-0424-y PMID: 17690969.

Social Security Administration, Annual Statistical Report on the Social Security Disability Insurance Program: 2010. No. 13-11826. August 2011: Disabled Beneficiaries Receiving Social Security, SSI, or Both. Table 68. Distribution of beneficiaries aged 18-64, by diagnostic group. Retrieved from https://www.ssa.gov/policy/ docs/statcomps/di_asr/index.html

Social Security Administration, Annual Statistical Report on the Social Security Disability Insurance Program: 2019. No. 13-11826. October 2020: Disabled Beneficiaries Receiving Social Security, SSI, or Both. Table 69. Distribution of beneficiaries aged 18-64, by diagnostic group. Retrieved from https://www.ssa.gov/policy/ docs/statcomps/di_asr/index.html

Szatmari, P., Bartolucci, G., Bremner, R., Bond, S., \& Rich, S. (1989). A follow-up study of high-functioning autistic children. Journal of Autism and Developmental Disorders, 19(2), 213-225. https:// doi.org/10.1007/BF02211842 PMID: 2745389.

Treffert, D. A. (1970). Epidemiology of infantile autism. Archives of General Psychiatry, 22(5), 431-438. https://doi.org/10.1001/archp syc.1970.01740290047006 PMID: 5436867.

United States Census Bureau, March 2018, 2017 National Population Projections Tables: Main Series Table 2 Retrieved from https:// www.census.gov/content/census/en/data/tables/2017/demo/poppr oj/2017-summary-tables.html

U.S. Bureau of the Census. Current Population Survey, 1962-2017. Retrieved from http://crr.bc.edu/wp-content/uploads/2015/10/ Avg_ret_age_men.pdf

Venter, A., Lord, C., \& Schopler, E. (1992). A follow-up study of highfunctioning autistic children. Journal of Child Psychology and Psychiatry, 33(3), 489-507. https://doi.org/10.1111/j.1469-7610. 1992.tb00887.x PMID: 1577895.

Vohra, R., Madhavan, S., \& Sambamoorthi, U. (2017). Comorbidity prevalence, healthcare utilization, and expenditures of Medicaid enrolled adults with autism spectrum disorders. Autism, 21(8), 995-1009. https://doi.org/10.1177/1362361316665222 PMID: 27875247.

Xu JQ, Murphy SL, Kochanek KD, Arias E. Mortality in the United States, 2018. NCHS Data Brief, no 355. Hyattsville, MD: National Center for Health Statistics. 2020. Retrieved from https://www. cdc.gov/nchs/products/databriefs/db355.htm

Yeargin-Allsopp, M., Rice, C., Karapurkar, T., Doernberg, N., Boyle, C., \& Murphy, C. (2003). Prevalence of autism in a US 
metropolitan area. JAMA, 289(1), 49-55. https://doi.org/10.1001/ jama.289.1.49 PMID: 12503976.

Yingling, M. E., \& Bell, B. A. (2019). Underutilization of early intensive behavioral intervention among 3-year-old children with Autism Spectrum Disorder. Journal of Autism and Developmental Disorders, 49(7), 2956-2964. https://doi.org/10.1007/s10803019-04005-0 PMID: 31016676.

Yuan, J., Li, M., \& Lu, K. (2021). Racial/ethnic disparities in the prevalence and trends of autism spectrum disorders in US children and adolescents. JAMA Network Open. 2021 4(3):e210771. https://doi. org/10.1001/jamanetworkopen.2021.0771

Zablotsky, B., Black, L. I., \& Blumberg, S. J. (2017). Estimated Prevalence of children with diagnosed developmental disabilities in the United States, 2014-2016. NCHS Data Brief, 291, 1-8. PMID: 29235982.
Zerbo, O., Qian, Y., Ray, T., Sidney, S., Rich, S., Massolo, M., \& Croen, L. A. (2019). Health care service utilization and cost among adults with autism spectrum disorders in a US integrated health care system. Autism in Adulthood, 1(1), 27-36. https://doi. org/10.1089/aut.2018.0004

Zuvekas, S. H., Grosse, S. D., Lavelle, T. A., Maenner, M. J., Dietz, P., \& Ji, X. (2020). Healthcare costs of pediatric autism spectrum disorder in the United States, 2003-2015. Journal of Autism and Developmental Disorders. https://doi.org/10.1007/s10803-02004704-z PMID: 33113106.

Publisher's Note Springer Nature remains neutral with regard to jurisdictional claims in published maps and institutional affiliations. 